\title{
CHARACTERIZATION OF BIODEGRADABLE BANANA FIBER REINFORCED COMPOSITE MATERIALS
}

\author{
Krunal Mahant ${ }^{1}$, Asad Shaikh ${ }^{2}$, Ishan Nadkarni ${ }^{3}$, Vedang Sharma ${ }^{4}$ \\ ${ }^{\text {I} S t u d e n t, ~ D e p a r t m e n t ~ o f ~ M e c h a n i c a l ~ E n g i n e e r i n g, ~ B R A C T ' s ~ V i s h w a k a r m a ~ I n s t i t u t e ~ o f ~ T e c h n o l o g y, ~ P u n e, ~}$ \\ Maharashtra, India \\ ${ }^{2}$ Student, Department of Mechanical Engineering, BRACT's Vishwakarma Institute of Technology, Pune, \\ Maharashtra, India \\ ${ }^{3}$ Student, Department of Mechanical Engineering, BRACT's Vishwakarma Institute of Technology, Pune, \\ Maharashtra, India \\ ${ }^{4}$ Student, Department of Mechanical Engineering, BRACT's Vishwakarma Institute of Technology, Pune, \\ Maharashtra, India
}

\begin{abstract}
According to industry representatives, the per capita consumption of plastic in India doubled from $4 \mathrm{~kg}$ in 2006 to $8 \mathrm{~kg}$ in 2010 and would touch the global average of $27 \mathrm{~kg}$ per person by 2020. Our mini project surrounds itself with biodegradable composites with Banana fibers as the fiber component, while the matrix used is babul bark gum, thus making the entire composite biodegradable and eco-friendly. This project outlines the fabrication and characterization of composites with fibers of length $10 \mathrm{~mm}$ to $15 \mathrm{~mm}$ and the fiber:matrix weight ratio 1:2. Its tensile strength was found to be $3.110 \mathrm{MPa}$ and flexural strength is found out to be 6.996 MPa. The composite formed is found to be useful as a biodegradable utensil, as well as a good thermal insulator.
\end{abstract}

Keywords: - banana fiber; biodegradable; natural matrix; babul bark gum; thermal insulation

\section{INTRODUCTION}

In the past two decades, the consumption of disposable products has increased tremendously and India generates more than 15,000 tonnes of plastic waste every day. Every year there is $15 \%$ increase in plastic consumption. This also includes polymer composites which are non-biodegradable in nature. In India about $1.5 \mathrm{M}$ acres of land is cultivated with banana plantations which yield about $3 \times 10^{5}$ tonnes of fiber. [11] Rare work has been done in the area of biodegradable composites. Conclusively, our project deals with the fabrication and characterization of natural composites reinforced by banana fibers while the matrix material used is babul bark gum. There are two major components when dealing with the preparation of a composite material - the fiber and the matrix. The fiber choice matters as the mechanical properties depend on the size, shape and orientation of the fibers in the composite. The matrix plays an important role with regard to the chemical properties of the composite. The chemical resistance, affinity to compounds, etc. is generally derived from the matrix used. [8] We have made use of Babul Bark Gum (Common Name-Dink) as the matrix to ensure the biodegradability of the product. One of the important factors to vary the mechanical properties of the composite is the fiber:matrix weight ratio, or the volume ratio. We have restricted focus of our project to weight ratio 1:2 (fiber:matrix) while preparing composites. The mechanical properties of the composite increase with increase in fiber content, but too much fiber content may cause the bonding to loosen up hence affecting the properties negatively. [3]

\subsection{Banana Fiber}

Banana Fiber generally occur as lignocelluloses material which consist of helically wound cellulose micro-fibrils in an amorphous matrix which is a combination of lignin and hemicelluloses. The cellulose content serves as a major deciding factor for mechanical properties as well as the micro-fibril angle. A high cellulose content and low microfibril angle impart desirable mechanical properties for banana fiber. The table shows mechanical properties of banana fibers of different diameters. [11] 
Table 1: Mechanical properties of banana fibers of different diameters

\begin{tabular}{|l|l|l|l|l|l|l|l|}
\hline $\begin{array}{l}\text { Sample } \\
\text { Number }\end{array}$ & $\begin{array}{l}\text { Diameter of } \\
\text { fiber } \\
(\boldsymbol{\mu m})\end{array}$ & $\begin{array}{l}\text { Initial } \\
\text { Young's } \\
\text { Modulus } \\
(\mathbf{G P a})\end{array}$ & $\begin{array}{l}\text { SD Initial } \\
\text { Young's } \\
\text { Modulus } \\
(\mathbf{G P a})\end{array}$ & $\begin{array}{l}\text { Breaking } \\
\text { Strength } \\
(\mathbf{M P a})\end{array}$ & $\begin{array}{l}\text { SD } \\
\text { Breaking } \\
\text { Strength } \\
(\mathbf{M P a})\end{array}$ & \% Strain & SD \% Strain \\
\hline 1 & 50 & 32.703 & 8.190 & 779.078 & 209.300 & 2.750 & 0.957 \\
\hline 2 & 100 & 30.463 & 4.689 & 711.661 & 239.614 & 2.469 & 0.798 \\
\hline 3 & 150 & 29.748 & 8.561 & 773.002 & 297.104 & 3.583 & 1.114 \\
\hline 4 & 200 & 27.698 & 7.083 & 789.289 & 128.558 & 3.340 & 0.688 \\
\hline 5 & 250 & 29.904 & 4.059 & 766.605 & 165.515 & 3.244 & 1.284 \\
\hline
\end{tabular}

\subsection{Babul Bark Gum}

The gum obtained from Acacia nilotica (also known as Gum of Arabia) i.e., babul bark gum occurs in form of rounded or ovoid tears about $1 \mathrm{~cm}$ in size and colour varies from pale yellow to brown according to age of the tree from which it was obtained.

Solubility: $50 \mathrm{gm} / 100 \mathrm{ml}$

Molecular weight: $2.3 \times 10^{6}$

Table 2: Chemical Composition

\begin{tabular}{|l|l|}
\hline Constituents & $\begin{array}{l}\text { Babul Bark Gum (Acacia } \\
\text { Nilotica) }\end{array}$ \\
\hline Ash (\%) & 2.5 \\
\hline Heavy metals (ppm) & $<20$ \\
\hline Moisture (\%) & 5.8 \\
\hline Protein (5) & 5.25 \\
\hline
\end{tabular}

\subsection{Failure and Load Sharing}

The deformation of a composite generally take place in 4 stages.

1. Both fiber and matrix deform in a linear elastic fashion.

2. The fiber continues to deform elastically but the matrix deforms non-linearly or plastically.

3. The fiber and matrix both deform non-linearly or plastically.

4. 4. The fibers fracture followed by a composite failure.

\subsection{Micromechanics of Failure and Failure Modes}

The internal material failure is generally observed in the following forms.

1. Breaking of Fibers

2. Microcracking of the Matrix

3. Separation of Fibers from the Matrix (Debonding)

4. Separation of Laminate from each other in a laminated composite.

\subsection{Equations}

Equation 1 Rule of Mixture

$$
\begin{aligned}
& \sigma_{\mathrm{c}}=\sum_{i=1}^{n} \sigma_{i} V_{i} \\
& E_{\mathrm{c}}=\sum_{i=1}^{n} E_{i} V_{i}
\end{aligned}
$$

Equation 2 Minimum volume for ductile fiber-based failure

$$
V_{\min }=\frac{\sigma_{\mathrm{mu}}-\left(\sigma_{\mathrm{m}}\right)_{\mathrm{si}}}{\sigma_{\mathrm{fu}}+\sigma_{\mathrm{mu}}-\left(\sigma_{\mathrm{m}}\right)_{\mathrm{E} i}}
$$

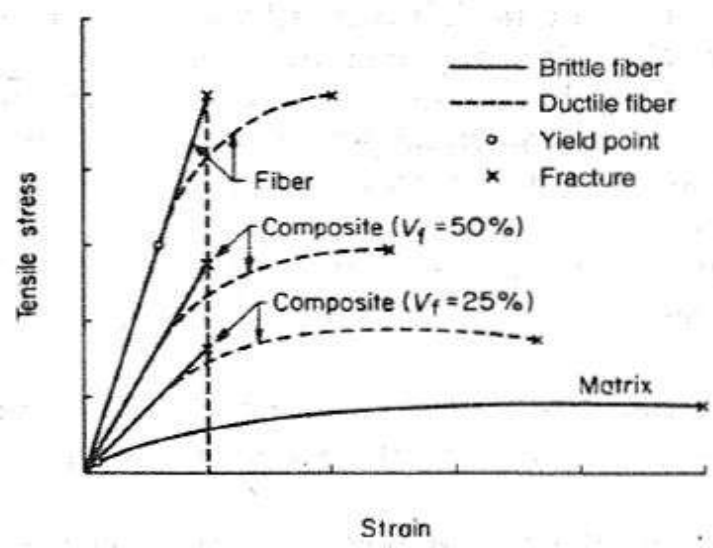

Fig 1: Stress-Strain Curves with different Volume fractions

\subsection{Literature Survey}

The mechanical behaviour of a natural fiber-based polymer composite depends on numerous factors, for example, fiber length and quality, matrix, fiber-matrix adhesion bond quality and so forth.

[1] have worked on the effect of surface treatment on the chemical properties of a composite and concluded that treated fibers exhibit higher tensile strength and shear strength as compared to untreated fibers. 
[2] have worked upon the effect of fiber wt. percent on the ultimate tensile strength, it was found that it was maximum at $15 \%$ wt. percent of fiber.

[3] reported that with increase in length of fibers from 10$25 \mathrm{~mm}$, the flexural properties increased, while the compressive strength was maximum at $15 \mathrm{~mm}$ and decreased as the length was increased. The elongation was found to be maximum at a fiber length of $15 \mathrm{~mm}$.

[4] The effect of geometric orientation of fibers in the layup/mould was studied and it was reported that kraft meshed fibers showed better physical and mechanical properties.

\subsection{Objectives}

We have observed that a lot of research has been done in studying the mechanical and physical properties of banana fiber reinforced composites, but very few of these composites were biodegradable, to this effect, our objectives list out as below:

- Fabrication of short, completely biodegradable natural fiber reinforced composite materials.

- $\quad$ Evaluate the mechanical properties such as tensile strength, flexural strength for such fabricated components.

- To find out the minimum material thickness required for producing disposable biodegradable utensils.

- $\quad$ To qualitatively study the thermal conductivity of these composites.

\section{METHODOLOGY / EXPERIMENTAL / COMPUTATIONAL}

The manufacturing processes for most composite materials hold close similarity to each other, in each, there are two major components - the fiber and the matrix.

Optional additives such as hardeners, accelerators may also be used during the manufacturing phase.

- The fiber used is banana fiber.

- $\quad$ The matrix material used are babul bark gum.

- $\quad$ No hardeners or accelerators were used.

\subsection{Hand Lay-Up Preparation Technique}

The hand lay-up technique is the oldest, simplest, and most commonly used method for the manufacture of both small and large reinforced products. A flat surface, a cavity (female) or a positive (male) mould, made from wood, metal, plastics, reinforced plastics, or a combination of these materials may be used. Fiber reinforcements and resin are placed manually against the mould surface. Thickness is controlled by the layers of materials placed against the mould. Once the mould is filled, it is allowed to dry and this the composite is formed.

\subsection{First Model - Proof of Concept}

Model: This attempt was a purely raw attempt, the wt. proportion of fiber was not considered. The matrix material used for this composite was Babul Bark Gum (Dink). The mould used was a basic metal diya exhibiting the shape of a bowl. [Fig. 1]

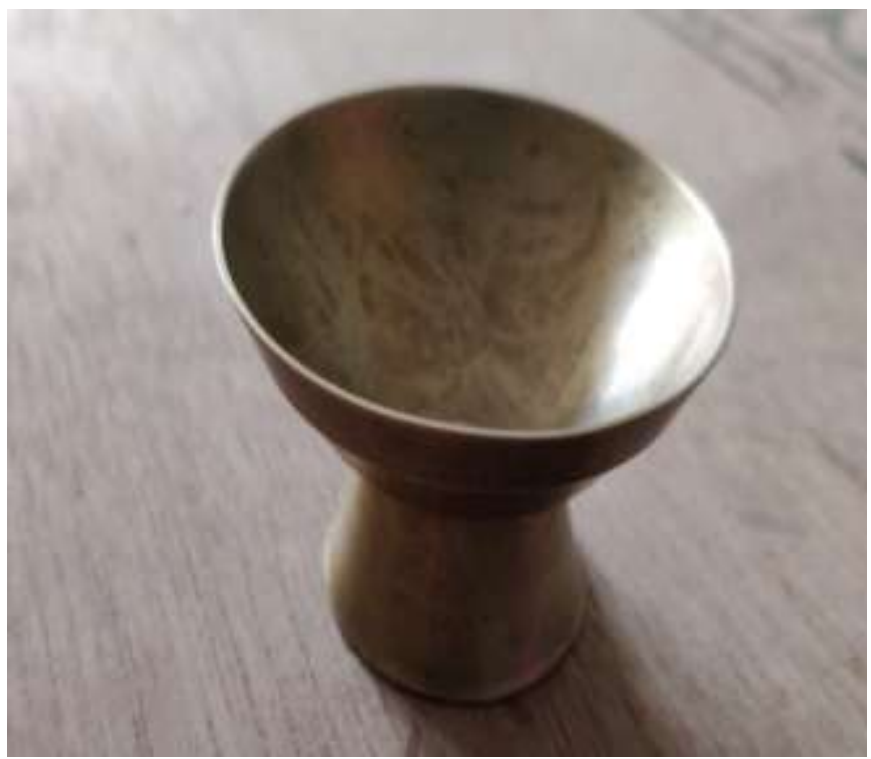

Fig 2: Mould for model I

\subsection{Further Models - Mechanical Testing}

The next batch of composites was to test the effect of weight proportions and length of fiber on the mechanical and physical behaviour of the composites.

1. ' $x$ ' grams of fiber was taken of required Fiber length and based on the weight ratio, appropriate amount of matrix (Babul bark gum) was taken.

2. Matrix material was dissolved in water. Water was added gradually while dissolving the matrix in it, such that a saturated solution was obtained.

3. Cuboidal moulds of size $80 \mathrm{~mm} \times 40 \mathrm{~mm} \times 10 \mathrm{~mm}$ were prepared from Galvanised Iron sheet of thickness $1.00 \mathrm{~mm}$

4. Composites was prepared using hand lay-up technique with different weight ratios and Fiber lengths. [Table I] The Fibers were arranged in random orientation.

5. Moulds were heated at a temperature of $70{ }^{\circ} \mathrm{C}$ for 15 minutes and then were left to dry under atmospheric conditions. Each mould took around 8 hours to dry completely.

6. Without applying any external heat source, it required on an average 1.5 days for drying up.

7. The composites with weight ratio $1: 1$ and 1:3 were not suitable for mechanical testing due to reasons mentioned in the results section [III.B.a.], thus we have restricted the testing to weight ratio of $1: 2$ and a fiber length of $10-20 \mathrm{~mm}$.

8. For Tensile Testing of composite with weight ratio $1: 2$ and fiber length $10-20 \mathrm{~mm}$, sample of thickness $3.5 \mathrm{~mm}$ was prepared according to standard ASTM D638.

9. For Flexural testing, sample of thickness $4 \mathrm{~mm}$ was prepared according to standard ASTM D790. 

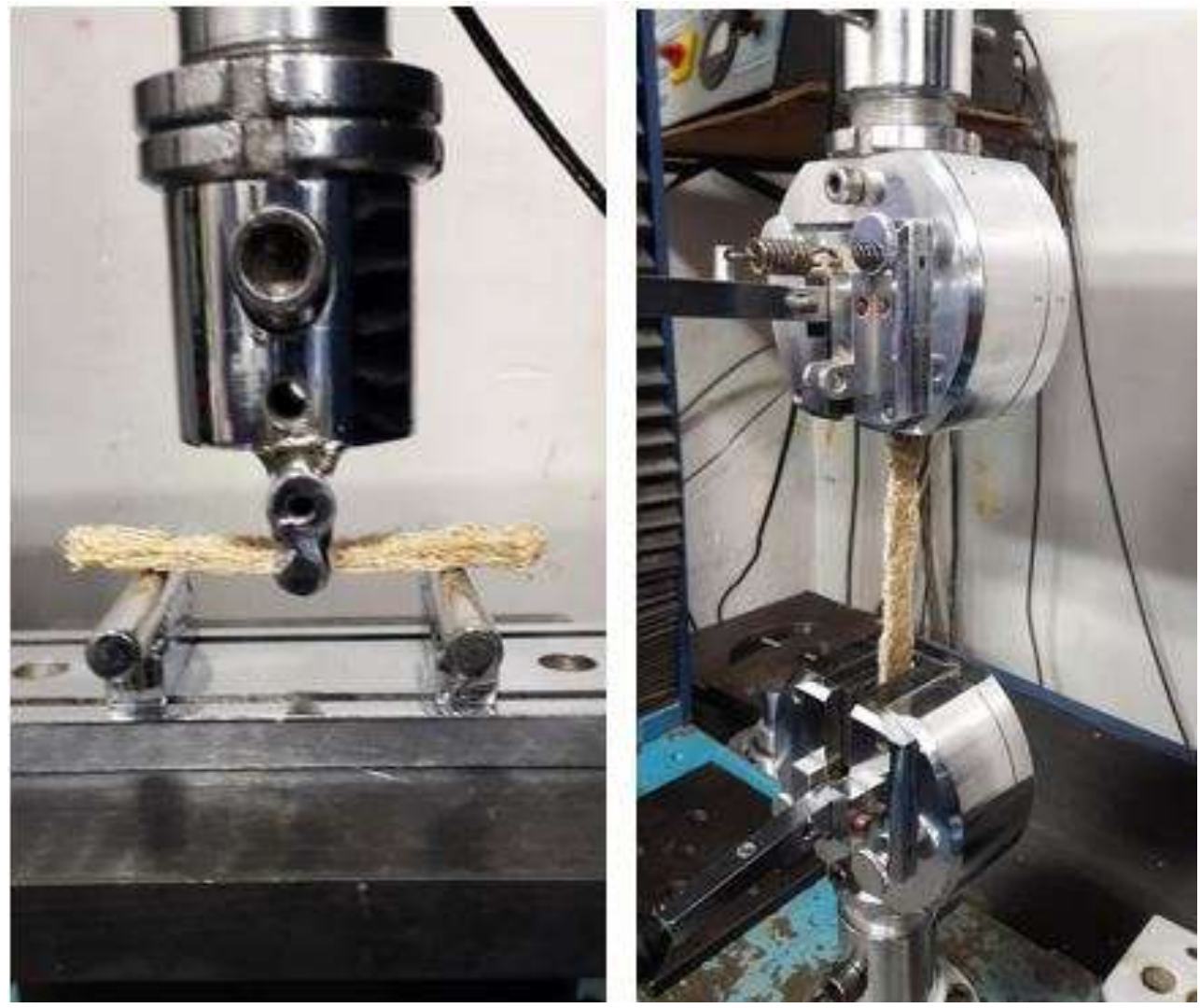

Fig 2: Tests, Flexural (Left), Tensile (Right)

Table 3: Composites with different fiber lengths and weight ratios

\begin{tabular}{|c|c|c|c|}
\hline \multirow[t]{2}{*}{ Composite } & \multirow{2}{*}{$\begin{array}{l}\text { Length } \\
\text { of Fiber }\end{array}$} & \multicolumn{2}{|c|}{ Weight Proportions } \\
\hline & & Fiber $(g)$ & Matrix (g) \\
\hline \multirow{3}{*}{$\begin{array}{l}\text { Banana Fiber } \\
+ \text { Babul Bark } \\
\text { Gum }\end{array}$} & \multirow{3}{*}{$\begin{array}{l}\text { Granular } \\
(<5 \mathrm{~mm})\end{array}$} & 10 & 10 \\
\hline & & 10 & 20 \\
\hline & & 10 & 30 \\
\hline \multirow{3}{*}{$\begin{array}{ll}\text { Banana } & \text { Fiber } \\
\text { +Babul } & \text { Bark } \\
\text { Gum } & \\
\end{array}$} & \multirow{3}{*}{$\begin{array}{l}10 \mathrm{~mm} \text { to } \\
20 \mathrm{~mm}\end{array}$} & 10 & 10 \\
\hline & & 10 & 20 \\
\hline & & 10 & 30 \\
\hline \multirow{3}{*}{$\begin{array}{ll}\text { Banana } & \text { Fiber } \\
+ \text { Babul } & \text { Bark } \\
\text { Gum } & \end{array}$} & \multirow{3}{*}{$\begin{array}{l}40 \mathrm{~mm} \text { to } \\
80 \mathrm{~mm}\end{array}$} & 10 & 10 \\
\hline & & 10 & 20 \\
\hline & & 10 & 30 \\
\hline
\end{tabular}

\subsection{Qualitative Thermal Testing}

1. First Matrix material was heated gradually on a plate with known temperature starting from $70{ }^{0} \mathrm{C}$ and gradually increasing the temperature.

2. Then a composite sample with dimensions $80 \mathrm{~mm} \mathrm{x}$ $40 \mathrm{~mm} \times 10 \mathrm{~mm}$ was placed on the plate at a temperature of $70{ }^{\circ} \mathrm{C}$ with its larger surface in contact with the plate and no considerable change in temperature was observed on the other side after 15 mins.

3. The temperature of the plate was increased till $100^{\circ} \mathrm{C}$, due to results given in result section [III.C].

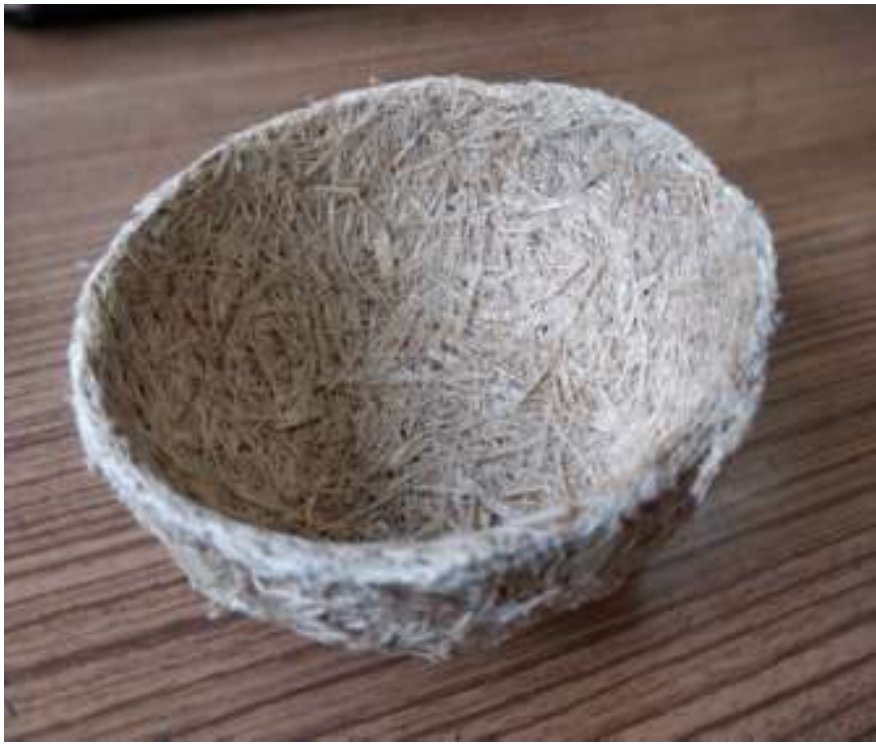

Fig 3: Successful biodegradable cutlery

\section{RESULTS AND DISCUSSION}

\subsection{Model 1}

The first attempt was done with only one side of the mould present, thus leaving one part of the solidifying composite exposed to the atmosphere, due to action of gravity and inadequacy of the matrix material, the part of composite facing the mould showed good smoothness and considerable 
interfacial bonding, while the other part showed wear of fibers and a rougher surface. Thus, concluded that exposed parts won't result in good composites and that the mould needs to keep the composite material compressed from both the sides. The model. [Fig. 2]

\subsection{Mechanical Testing}

1. When the weight ratio 1:1 was considered, the amount of matrix material was found be inadequate to properly hold the fibers together, thus resulting is weaker interfacial bonding. [Fig. 3] When the case was of wt. ratio $1: 3$, the matrix material was more than the required amount thus separated out from fibers. In cases of granular fiber length $(<5 \mathrm{~mm})$ or fibers longer than $50 \mathrm{~mm}$ in length, the mechanical properties were again very low to have any practical application.

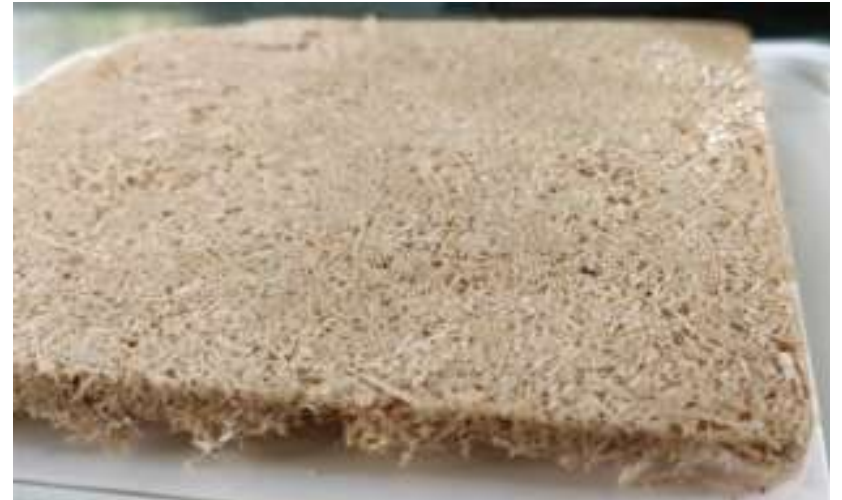

Fig 4: Weight ratio 1:1, fiber length $<5 \mathrm{~mm}$

2. For sample tested for tensile test following result was obtained:
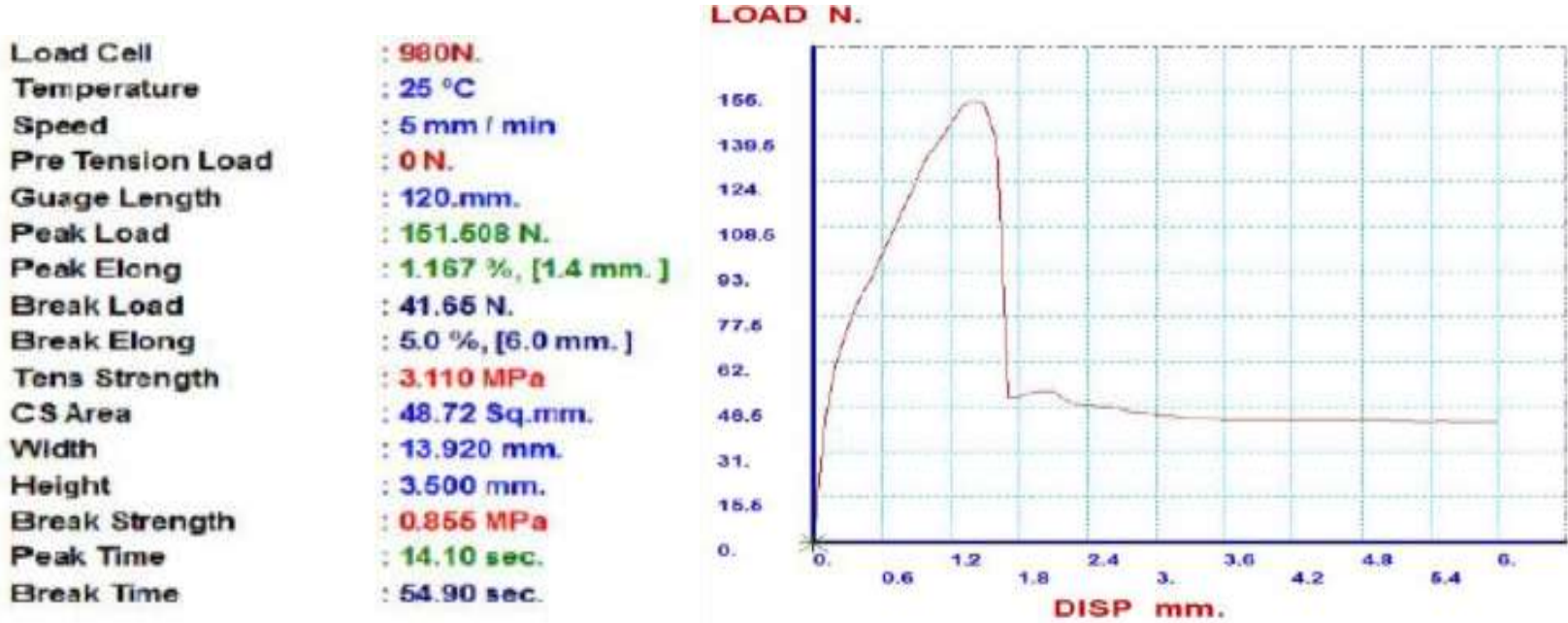

3. For Flexural strength testing following result was obtained:
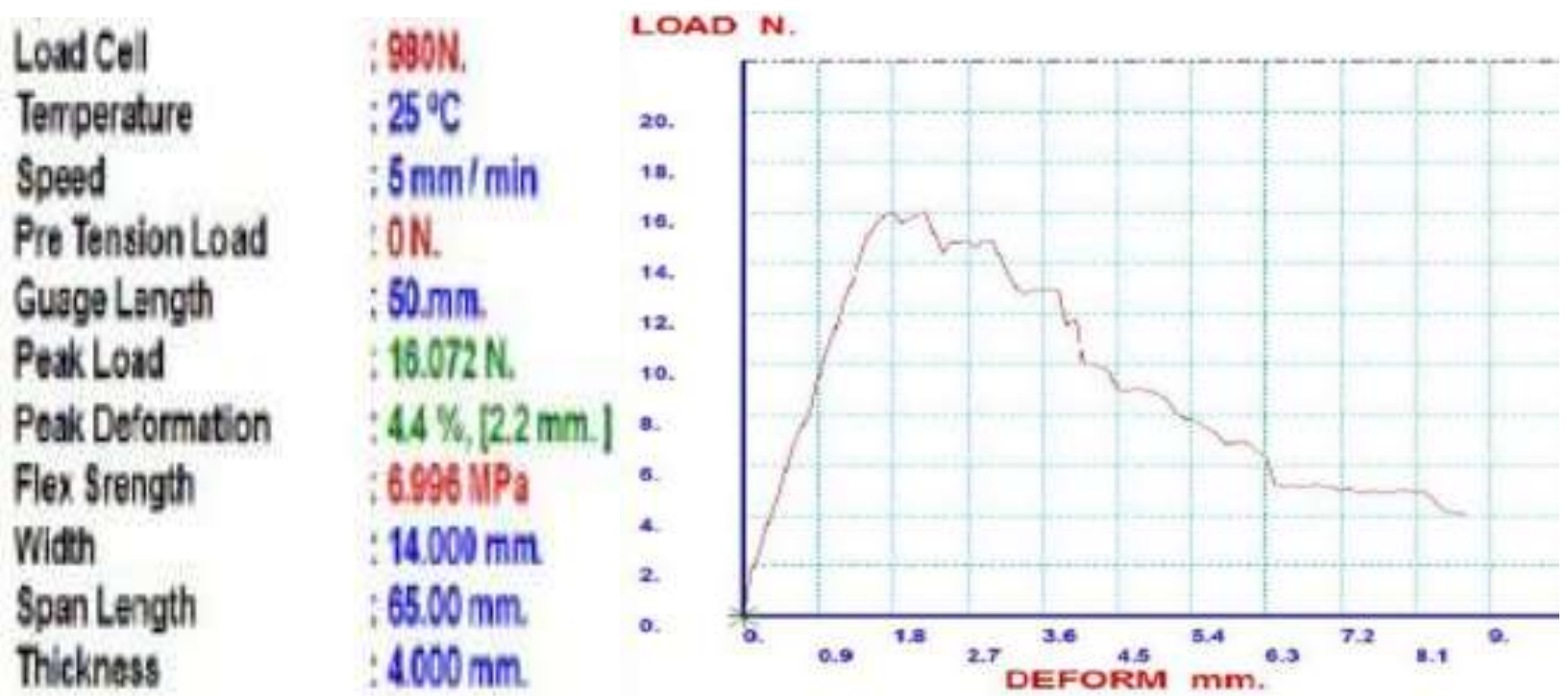


\subsection{Thermal Conductivity}

1. Matrix material offers resistance to higher temperature in terms of conductivity but burns without flames at a temperature above $100{ }^{\circ} \mathrm{C}$ and becomes brittle in nature after burning.

2. Thus, the composite was tested for thermal conductivity with temperature below $100{ }^{0} \mathrm{C}$ on one side of the sample.

3. It was found that material possesses excellent thermal insulation property with negligible change in temperature change on the free end of sample.

\section{CONCLUSION}

- Biodegradable composite materials were made using banana fiber and babul bark gum. Since Babul bark gum is soluble in water, these composites can be used in wet environment by applying a water-resistant lamination.

- The mechanical properties of composite with fiber:matrix weight ratio as 1:2 and fiber length $10-15 \mathrm{~mm}$ were evaluated, it was found that this materials is mechanically weak and cannot be used for any structural application.

- However, it can be used for making disposable biodegradable utensils. Minimum thickness required to make this kind of utensils was found out experimentally to be $1 \mathrm{~mm}-2 \mathrm{~mm}$.

- For making reusable utensils thickness greater than $5 \mathrm{~mm}$ can be used.

- Since this material has good thermal insulation property at temperature less than $100{ }^{\circ} \mathrm{C}$, this composite can be used for thermal shielding in rooftops of cars, or in helmets for keeping the user end cooler than the outside temperature.

\section{REFERENCES}

[1] Merlini C., Soldi V., Barra G.M.O, Influence of Fiber Surface Treatment and Length on Physico-Chemical Properties of Short Random Banana Fiber Reinforced Castor Oil Polyurethane Components, Polymer Testing, 30, 2011, pp. 833-840.

[2] Shankar P. S., Reddy K.T., Sekhar V. C., Mechanical Performance and Analysis of Banana Fiber Reinforced Epoxy Composites, International Journal of Recent Trends in Mechanical Engineering, Vol. 1, 2013, pp.1-10.

[3] Sumaila M., Amber I., Bawa M., Effect of Fiber Length on the Physical and Mechanical Properties of Random Oriented, Nonwoven Short banana (Musa Balbisiana) Fiber/Epoxy Composite, Asian Journal of Natural \& Applied Sciences, 2, 2013, pp. 39-49.

[4] Laban B. G., Corbiere-Nicollier T., Leterrier Y., Lundquist L., Manson J. -A. E., Jolliet O., Life Cycle Assessment of Biofibers Replacing Glass Fibers as Reinforcement in plastics, Resources Convertion and Recycling, 33(2001), pp. 267-287.

[5] Sujeet Kumar, Study on Mechanical Behaviour of Banana Fiber Reinforced Exopy Composites, B.Tech
Thesis, National Institute of Technology, Rourkela, India, 2004.

[6] J. Sahari and S.M. Sapuan, Natural Fiber Reinforced Biodegradable Polymer Composites, Reviews on Advanced Material Science, 2012.

[7] Olof Gabrielsson, Manufacturing of PLA-based composites reinforced with cellulose fibers and fibrils, Chalmers University of Technology, Gothenburg, Sweden, 2013.

[8] M. Jawaid, Anshu A. Singh, Sadaf Afrin and Zoheb Karim, Green Composites: Versatile Material for Future, Springer International Publishing, Green Biocomposites, 2017.

[9] Jie Cheng, Influence of Fiber Hybridisation on Dynamic Mechanical Behaviour of Natural Based Composites, M.Tech Thesis, Victoria University of Technology, Melbourne, Australia, 1998.

[10] Bhagwan D. Agarwal, Lawrence J. Browtman, K. Chandraskhekhara, Analysis and Performance of Fiber Composites, Wiley International Publishing, Delhi, India, 2006.

[11] Kulkarni, A.G., Satyanarayana, K.G., Rohatgi, P.L. and Vijayan, K., Mechanical Properties of Banana Fibers, Journal of Material Science, pp 2290-2296, 1982.

[12] Akash Koli, Study on Thermal and Acoustic Characteristics of Bagasse fiber reinforced epoxy composites, M.Tech Thesis, National Institute of Technology, Rourkela, India, 2015. 